\title{
Characterisation of a spumavirus Gag protein
}

\author{
David C Goldstone ${ }^{1}$, Thomas G Flower ${ }^{1}$, Neil J Ball ${ }^{*}$, Marta Sanz-Ramos ${ }^{2}$, Melvin W Yap ${ }^{2}$, Roksana W Ogrodowicz ${ }^{1}$ \\ Nicole Stanke ${ }^{3}$, Juliane Reh ${ }^{3}$, Dirk Lindemann ${ }^{3}$, Jonathan P Stoye ${ }^{2}$ \\ From Frontiers of Retrovirology: Complex retroviruses, retroelements and their hosts \\ Cambridge, UK. 16-18 September 2013
}

\section{Background}

Human prototypic foamy virus (HPFV) belongs to the spumaretrovrinae subfamily and is an attractive vector candidate for gene therapy [1] as it is apathogenic. The Gag protein is not cleaved into matrix (MA), capsid (CA) and nucleocapsid (NC) as occurs in orthoretroviruses; rather, it is able to perform the roles of these proteins as a single polypeptide [2]. Foamy virus Gag proteins are targets for restriction factors such as Trim5 $\alpha$ [3] and also interact with the aminoterminal leader peptide of the envelope protein (Env). This Gag-Env interaction is essential for budding of viral particles from the host cell $[4,5]$.

\section{Materials and methods}

To investigate HPFV Gag assembly and Gag-Env interactions we have undertaken combined structural and biophysical studies using X-ray crystallography, NMR, multi-angle laser light scattering (MALLS) and analytical ultracentrifugation (AUC).

\section{Results}

An N-terminal domain (NtD) of HPFV-Gag has been identified which is functionally related to CA and MA in other retroviruses despite very low sequence homology. Structural and solution studies of the HPFVGagNtD reveal that it forms a very stable homodimer which interacts through an extended coiled-coil region. A separate region of HPFV-Gag that exhibits a propensity for selfassociation has been identified and preliminary structural and biophysical analysis suggests that it is able to form homodimers with a dissociation constant of approximately $30 \mu \mathrm{M}$. The molecular basis of the Gag-Env interaction has been structurally characterised and mutagenic studies, both in vitro and in vivo, have revealed the importance of the individual residues involved in this interaction.

\section{Conclusions}

In stark contrast to orthoretroviral capsid which selfassociates to form a predominantly hexameric lattice, the HPFV-Gag-NtD forms stable homodimers in solution. The identification of a secondary self-association region suggests that these dimers may undergo further multimerisation in the full-length Gag protein. Comparison of Trim $5 \alpha$ specificity between foamy viruses suggests that the recognition site resides on the exposed surface of the $\mathrm{N}$-terminal domain of the Gag protein.

\section{Authors' details}

${ }^{1}$ Division of Molecular Structure, MRC National Institute for Medical Research, The Ridgeway, Mill Hill, London, NW7 1AA, UK. ²Division of Virology, The Ridgeway Mill Hill, London, NW7 1AA, UK. ${ }^{3}$ Institute of Virology, Technische Universität Dresden, Fetscherstraße 74, 01307 Dresden, UK.

Published: 19 September 2013

References

1. Lindemann D, Rethwilm A: Foamy virus biology and its application for vector development. Viruses 2011, 3:561-585.

2. Flügel R, Pfrepper K: Proteolytic processing of foamy virus Gag and Pol proteins. Curr Top Microbiol Immunol 2003, 277:63-88.

3. Yap M, Lindemann D, Stanke N, Reh J, Westphal D, Hanenberg H, Ohkura S, Stoye J: Restriction of foamy viruses by primate Trim5a. J Virol 2008 82:5429-5439.

4. Wilk $T$, Geiselhart $V$, Frech $M$, Fuller $S$, Flügel $R$, Löchelt $M$ : Specific interaction of a novel foamy virus Env leader protein with the $\mathrm{N}$ terminal Gag domain. J Virol 2001, 75:7995-8007.

5. Pietschmann $T$, Heinkelein $M$, Heldmann $M$, Zentgraf $H$, Rethwilm A, Lindermann D: Foamy virus capsids require the cognate envelope protein for particle export. J Virol 1999, 73:2613-2621.

doi:10.1186/1742-4690-10-S1-P3

Cite this article as: Goldstone et al:: Characterisation of a spumavirus Gag protein. Retrovirology 2013 10(Suppl 1):P3. 